\title{
Information Technology and the Knowledge Elites
}

\author{
Gilles Saint-Paul ${ }^{1}$ \\ Université des Sciences Sociales, Toulouse; \\ CEPR, CES and IZA.
}

July 8, 2003

\footnotetext{
${ }^{1}$ Address for correspondence: Gilles Saint-Paul, MF 206, GREMAQ-IDEI, Université des Sciences Sociales, Manufacture des Tabacs, Allée de Brienne, 31000 Toulouse, FRANCE. This paper has benefitted from suggestions by Michael Piore and Daron Acemoglu, as well as comments from seminar participants at Universitat Pompeu Fabra, Barcelona, Humboldt University, Berlin, and the NBER Summer Institute workshop on macroeconomic perspectives.
} 


\begin{abstract}
I study a model where Information Technology, while typically increasing overall inequality, is likely to harm some people at intermediate and high levels of the distribution of income but to benefit people at the bottom. Within a given occupation it may harm some workers while benefitting others; and it may either reduce or increase the proportion of knowledge workers in employment. In my model, knowledge (in a broad sense) is an input into the production function of human capital, and is also a "quality" good in the sense that one cannot buy it from several low-quality producers instead of one high-quality one. People differ in their exogenous ability and ability is complementary with the quality of the knowledge input in the production of human capital. An improvement in IT is modelled as an increase in the number of people who can buy knowledge from one producer. I show that the economy organizes itself in a succession of clusters of ability levels, called "knowledge ladders", where a member of a given ladder buys knowledge from a worker in the subsequent ladder and sells it to a worker of the preceding ladder. The return to human capital increases as one moves up the knowledge ladder. The economic mechanism considered here rests on the view that IT makes the acquisition of knowledge cheaper, which intensifies competition among workers specialized in knowledge production. Those who lose in such competition end up displaced to occupations with a lower knowledge intensity; their wages fall, which reduces inequality between them and the least skilled. Those who win can spread their ability over a larger market and because of that enjoy a larger increase in wages than the least skilled, which tends to increase inequality. The least skilled do not participate in this competition, as they are not specialized in knowledge production; they gain in absolute terms because of their cheaper access to knowledge.
\end{abstract}

JEL: J3, I2, O3, O4

Keywords: Income distribution, Information technology, Computers, Worker displacement, Human capital, Overlapping generations, Knowledge, Worker assignment. 


\section{Introduction}

Skilled-biased technical change, especially the diffusion of computers and information technology, is widely believed to be responsible for the observed rise in inequality and the fall in living standards at the bottom of the earnings distribution. ${ }^{1}$ The idea is that unskilled production workers can be advantageously substituted by skilled workers using computers. Yet direct evidence about this mechanism is quite mixed $^{2}$. On the one hand, there exist industry-level studies that suggest a positive correlation between the use of computers and the demand for skilled workers at the industry level. ${ }^{3}$ On the other hand, plant level evidence sometimes contradicts this view ${ }^{4}$, or suggests that this does not seem to be the case for many other ITs ${ }^{5}$; and results that showed a positive, causal impact of computer use on wages have been challenged $^{6}$. It is also sometimes argued that substitution of non production to production workers has typically led, not followed, the IT revolution ${ }^{7}$.

This paper studies a model where the effect of IT is far more complex than usually assumed. It is shown that IT, while typically increasing overall inequality, is likely to harm some people at intermediate and high levels of the distribution of income but to benefit people at the bottom; that within a given occupation it may harm some workers while benefitting others; and that it may either reduce or increase the proportion of knowledge workers in employment, depending on the response of the overall demand for knowledge

\footnotetext{
${ }^{1}$ For statements of this view, see Krueger (1993), Bound and Johnson (1992), OECD (1994), Krugman (1994), Gottschalk and Smeeding (1997)

${ }^{2}$ A critical survey can be found in Howell et al. (1998).

${ }^{3}$ Berndt et al. (1992), Berman et al. (1994), Autor et al. (1996), who typically point out that IT is associated with upskilling and an increase in the share of nonproduction employment.

${ }^{4}$ Cappelli (1993).

${ }^{5}$ See Doms et al. (1997).

${ }^{6}$ See the critique of Krueger (1993) by DiNardo and Pischke (1997) and Entorf et al. (1999). Doms et al. (1997) do not find an impact on wage differentials of computerization.

${ }^{7}$ Howell (1997) argues that the rise in the ratio of non-production to production workers highlighted by Berman, Bound, and Griliches (1994) stops in 1983, while Gordon (1996) finds that the share of non production workers ends up declining after 1985.
} 
to the implied reduction in the cost of acquiring it.

The central economic mechanism considered here is quite different from the idea that computers are substitute for unskilled workers; it rests on the view that IT makes the acquisition of knowledge cheaper, which intensifies competition among workers specialized in knowledge production. Those who lose in such competition end up displaced to occupations with a lower knowledge intensity; their wages fall, which reduces inequality between them and the least skilled. Those who win can spread their ability over a larger market (as in Rosen $(1981,1982)$ ) and because of that enjoy a larger increase in wages than the least skilled, which tends to increase inequality. The least skilled do not participate in this competition, as they are not specialized in knowledge production; they gain in absolute terms because of their cheaper access to knowledge.

In my model, knowledge (in a broad sense) is an input into the production function of human capital, and is also a "quality" good in the sense that one cannot buy it from several low-quality producers instead of one highquality one. This latter property plays a key role in the results, by allowing IT to differentially affect the wages of people who produce the same good (knowledge) but have different skills. People differ in their exogenous ability and ability is complementary with the quality of the knowledge input in the production of human capital.

I show that the economy organizes itself in a succession of clusters of ability levels, called "knowledge ladders", where a member of a given ladder buys knowledge from a worker in the subsequent ladder and sells it to a worker of the preceding ladder. The return to human capital increases as one moves up the knowledge ladder.

Next I consider the impact of an improvement in information technology, which is modelled as a reduction in the number of people from whom one has to buy knowledge. I show that such a shift increases the gap in the rate of return to human capital between two consecutive ladders, and at the same time leads to a displacement of the least able workers within each ladder to 
the inferior one. Another central result is that while an improvement in IT may increase wages for all worker types in the long run, its impact effect is to reduce wages for some workers who are displaced to lower knowledge levels. Those at the lowest level, i.e. direct production workers, gain in terms of absolute wages as they have access to a cheaper knowledge input. They experience a relative loss with respect to knowledge workers who are not displaced to a lower level, but a gain with respect to those who are displaced.

These wage effects are consistent with Mishel and Bernstein's (1994) finding that IT actually equalize wages at the bottom of the distribution of income, while increasing inequality at the top. There also exists some direct evidence that IT displaces workers at fairly high income levels. Cooke (2000), who specifically looks at prospects for workers in the IT industry, argues that "[while] companies are offering above average compensation packages to attract skilled IT workers, other IT workers risk being replaced by new technologies or simply a more efficient labor market". Further below, she states that "in the past, for example, IT occupations related to mainframeoriented processing such as keypunch operators, were eliminated or redefined as the technology evolved towards network-based, client-server computing. In recent years, computer operators that monitor and maintain large computer systems have begun to be replaced by self-monitoring, low maintenance systems." Similarly, Veneri (1998), reports a stagnation in the demand for computer programmers despite the explosion of computer use. This is presumably due to increased standardization and portability of programs, so that only the best programmers have kept their jobs. Interestingly, she also reports that the wages of programmers grow at about the same (high) rate as other IT professions. It is also known that in the nineties, white-collar workers were more exposed to displacement than in earlier decades. ${ }^{8}$

The paper is related to several strands of theoretical literature. One strand has insisted on "span of control" effects, the increasing returns they

\footnotetext{
${ }^{8}$ See American Management Association (2000).
} 
generate, and their implications for the distribution of income and the allocation of talent. This includes Calvo and Wellisz (1979), Rosen (1981,1982), Murphy, Shleifer and Vishny (1993), Garicano (2000). This type of effect is also key to the present paper, which differs from this literature in many respects, in particular in that it focuses on information technology and the organization of the labor market in successive knowledge ladders. Another strand is interested in the role of technologies that are more intensive in human capital (Acemoglu (1999), Zeira (1998), Caselli (1998), Galor and Moav (1998), Rubinstein and Tsiddon (1998), Beaudry and Green (2000)). The present paper differs from that strand in that rather than assuming a change in key elasticities of the production function, it explicitly recognizes, using a single production function, that improvements in IT allows knowledge to be spread over more people. Hence the technical change that we consider is not skilled biased by construction; rather, its effect on inequality is a general equilibrium consequence of the easier replicability of symbols and of the importance of knowledge quality.

Closer in spirit is the paper by Saint-Paul (2001). In both cases, knowledge is an indivisible good which is more valued by more productive agents. In Saint-Paul (2001), however, knowledge is a spillover exerted by creative people within networks. An improvement in IT increases these spillovers, in such a way that the poorest workers cannot be harmed; furthermore inequality goes up and then down as IT improves. ${ }^{9}$ Here, knowledge is traded, and an improvement in IT induces people to buy knowledge from fewer, but better people, which redistributes from "stars" to "superstars". The overall impact on inequality is similar to my previous paper, but the economic mechanism analyzed here is quite different. Furthermore, the present model captures the previously ignored phenomenon of worker displacement between knowledge ladders.

The next section sets up the basic model, which is an overlapping generations model of human capital accumulation, where in order to acquire human

\footnotetext{
${ }^{9}$ See Saint-Paul (2001) for details.
} 
capital one needs to buy knowledge of some quality from members of the previous generation. . Section 3 studies steady state equilibria, while section 4 analyzes transitional dynamics toward the steady state. Section 5 deals with two extensions. First, it allows the demand for knowledge to be elastic to its cost by assuming that some workers can 'opt out' of the knowledge economy by not acquiring human capital. Second, it shows how the model can be extended to take balanced growth into account, and analyzes the impact of population growth and productivity growth on the distribution of income. Section 6 concludes.

\section{Model set-up}

We consider an overlapping generation, open economy which can borrow and lend at a fixed real interest rate $r$. For notational simplicity we shall assume $r=0$. People live for two periods. The size of each cohort is fixed and normalized to one.

In the first period of their life, the young train themselves by buying knowledge. This determines their human capital. In the second period of their life they work and consume. They can either work in the production sector or sell knowledge to the next generation of young.

The young generation's agents differ in innate ability $g$. It is distributed over $[0,+\infty)$ with a Poisson distribution. Its density is given by

$$
f(g)=\gamma e^{-\gamma g}
$$

In order to acquire human capital, a young worker must buy knowledge from a fraction $s$ of an old worker, where $s<1$. If $b^{*}$ is the human capital of that knowledge supplier, the young worker's human capital is given by the following human capital production function:

$$
b=B e^{\lambda g} b^{* \alpha},
$$


where $B, \lambda$, and $\alpha$ are positive constants. Furthermore, $\alpha<1$, so that the human capital production function exhibits decreasing marginal returns to the knowledge supplier's human capital.

This specification implies that knowledge is not a homogeneous input: it has to be bought from exactly $s$ people. One cannot substitute two mediocre teachers for a good one. Furthermore, knowledge is assumed to be complementary with ability: people with greater ability get a higher marginal return from increasing the skills of the people from whom they learn.

$s$ captures the efficiency of information technology. The smaller $s$, the lower the working time of an old knowledge supplier that is needed in order to train one young worker - i.e. the greater the number of people who can use one person's knowledge.

We shall assume that $\gamma>\lambda$, which makes sure that the cross-sectional moments of productivity are well defined.

In the production sector, which is perfectly competitive, the production function is linear and given by

$$
Y=A H
$$

where $H$ is the aggregate amount of human capital employed in that sector. Consequently, an old agent of human capital $b$ who works in the production sector produces an output equal to $A b$. Contrary to what occurs in the knowledge sector, human capital enters in a homogeneous way in the production of physical output. In that sector, the same aggregate amount of human capital can be obtained by hiring a few high-skill workers or many low-skill workers.

Literally speaking, this is a model of human capital accumulation over the life cycle by successive cohorts. At a more metaphorical level, however, it may also apply to higher frequency phenomena and be used to understand the economy-wide organization of production. $b$ would then more broadly interpreted as a set of intangible, intermediate inputs (organizational skills, ideas, supervision, information, etc.) that allow to boost productivity in the 
final goods sector. ${ }^{10}$

The questions we are interested in are the following: how does the equilibrium distribution of human capital look like? How are knowledge producers assigned to knowledge consumers? Who specializes in knowledge production? What is the distribution of income? How does a change in $s$ affect these parameters?

These characteristics are represented by an equilibrium wage schedule $\omega(b)$, an equilibrium distribution of skills represented by a function $b(g)$ which tells us what is the human capital of an agent with ability $g$, and an equilibrium pair of knowledge assignment functions $b^{*}(g)$ (resp. $g^{*}(g)$ ), which tell us about the human capital (resp. ability) of the agent from whom a young agent with skill $g$ buys knowledge. We now analyze the equilibrium values of these functions.

\section{$3 \quad$ Steady state}

We first characterize a steady state where these functions are invariant over time. In this case, we must have:

$$
b\left(g^{*}(.)\right) \equiv b^{*}(.)
$$

The young's maximization problem is:

$$
\max _{b} \omega\left(B e^{\lambda g} b^{\alpha}\right)-s \omega(b) .
$$

Assuming that $\omega($.$) is locally differentiable, the first-order condition is { }^{11}$

$$
\omega^{\prime}\left(B e^{\lambda g} b^{\alpha}\right) \alpha B e^{\lambda g} b^{\alpha-1}=s \omega^{\prime}(b) .
$$

\footnotetext{
${ }^{10}$ One may argue that in such a case an infinite horizon framework would be more appropriate. However, Bewley (1980) and Townsend (1980) have developed models of imperfect access to credit markets whose structure is quite similar to OLG models.

${ }^{11}$ It turns out that the equilibrium wage schedule we construct is not differentiable at its critical points. In such a case, however, it is right- and left- differentiable, and the first-order condition (5) must be replaced with the following pair of inequalities:
}

$$
\omega_{R}^{\prime}\left(B e^{\lambda g} b^{\alpha}\right) \alpha B e^{\lambda g} b^{\alpha-1} \leq s \omega_{R}^{\prime}(b)
$$


Our central result is that depending on parameter values, the economy can be in one of two regimes. In regime I all workers are indifferent between knowledge production and output production. In regime II workers are entirely specialized in knowledge production above some ability level, and a knowledge "chain" arises in a way made clear below.

Let us first describe the equilibrium in regime $\mathrm{I}$.

PROPOSITION 1 - Assume

$$
s^{\frac{\gamma(1-\alpha)}{\lambda}-1} \geq \alpha^{\frac{\gamma(1-\alpha)}{\lambda}} .
$$

and

$$
\alpha \geq s
$$

then there exists a steady state such that

(i) The wage schedule is given by $\omega(b)=A b, \forall b$

(ii) All knowledge workers are indifferent between knowledge production and output production.

(iii) The knowledge assignment function $g^{*}(g)$ is given by

$$
g^{*}(g)=g+\frac{1-\alpha}{\lambda} \ln \frac{\alpha}{s}
$$

(iv) The knowledge assignment function $b^{*}(g)$ is

$$
b^{*}(g)=\left(\frac{\alpha B e^{\lambda g}}{s}\right)^{\frac{1}{1-\alpha}}
$$

(v) The human capital of an agent with ability $g$ is

$$
b(g)=B^{\frac{1}{1-\alpha}}\left(\frac{\alpha}{s}\right)^{\frac{\alpha}{1-\alpha}} e^{\frac{\lambda g}{1-\alpha}}
$$

and

$$
\omega_{L}^{\prime}\left(B e^{\lambda g} b^{\alpha}\right) \alpha B e^{\lambda g} b^{\alpha-1} \geq s \omega_{L}^{\prime}(b),
$$

where the $R$ and $L$ subscripts denote the right and left derivatives, respectively. 
Consequently, $b$ is distributed over $\left[b_{0},+\infty\right)$ with density $f_{0}(b)$ given by

$$
f_{0}(b)=\frac{\gamma(1-\alpha)}{\lambda} b_{0}^{\frac{\gamma(1-\alpha)}{\lambda}} b^{-\frac{\gamma(1-\alpha)}{\lambda}-1},
$$

with $b_{0}=b(0)=B^{\frac{1}{1-\alpha}}\left(\frac{\alpha}{s}\right)^{\frac{\alpha}{1-\alpha}}$.

PROOF - See Appendix.

If $\gamma(1-\alpha) / \lambda \leq 1$, then condition (6) is always satisfied and regime I holds for all $s \leq \alpha$. In the more interesting case when $\gamma(1-\alpha) / \lambda>1$, it holds for $s \in\left[\alpha^{\frac{\gamma(1-\alpha)}{\gamma(-\alpha)-\lambda}}, \alpha\right]$.

In this regime, knowledge producers are always indifferent between knowledge and goods production. The marginal return to human capital is constant throughout the distribution of skills and equal to $A$, its marginal productivity in the output sector. The explanation is as follows. At a constant marginal return to human capital equal to $A$, workers with ability $g$ want to purchase knowledge from workers with ability $g^{*}(g)$. The density of workers around $g^{*}(g)$ is larger than $s$ times the density of workers around $g$. In other words, there are more than enough workers willing to supply the amount of knowledge demanded by workers with ability $g$. Consequently, in equilibrium these workers must be indifferent between supplying knowledge or working in the production sector, which implies that the marginal return to human capital is pinned down by the production sector. This validates the assumption that it is equal to $A$.

At the bottom of the distribution of income, i.e. for workers with ability lower than $\frac{1-\alpha}{\lambda} \ln \frac{\alpha}{s}$, the demand for knowledge workers is zero. Therefore, these workers are entirely specialized in production, earning also $A$.

An improvement in information technology, i.e. a reduction in $s$, shifts the distribution of human capital, and therefore income, homothetically. All worker types earn more and relative inequality is unchanged. This is because while people buy knowledge from more able workers, there is a "reserve 
army" of knowledge suppliers at marginal cost $s A$ at any skill level, since a positive fraction of any skill type works in the production sector. Therefore, the demand shift in favor of higher quality knowledge suppliers is matched by a corresponding movement from production to knowledge among high quality workers, without any change in wages. ${ }^{12}$ At the same time the least able knowledge producers (those whose ability is close to the initial value of $\frac{1-\alpha}{\lambda} \ln \frac{\alpha}{s}$ ) become entirely specialized in production.

The next proposition describes the more interesting regime where some ability levels are entirely specialized in knowledge production. ${ }^{13}$

PROPOSITION 2 - Assume

$$
s^{1-\frac{\lambda}{\gamma(1-\alpha)}} \leq \alpha .
$$

Then there exists a steady state such that

(i) The knowledge assignment function $g^{*}(g)$ is given by

$$
g^{*}(g)=g+\frac{1}{\gamma} \ln \frac{1}{s}
$$

(ii) There exists a sequence of critical ability levels $\left(g_{0}, g_{1}, \ldots, g_{i}, \ldots\right)$ such that

a. $g_{i}=-i / \gamma \ln s$, implying $g_{0}=0$.

b. people such that $0 \leq g \leq g_{1}$ are entirely specialized in the production of physical output

c. people such that $g_{i} \leq g \leq g_{i+1}$ are entirely specialized in knowledge production. They sell knowledge to workers in $\left[g_{i-1}, g_{i}\right]$ and buy it from workers in $\left[g_{i+1}, g_{i+2}\right]$

\footnotetext{
${ }^{12}$ It is easy to check that for $g \geq \frac{1-\alpha}{\lambda} \ln \frac{\alpha}{s}$, a constant fraction $s^{(1-\alpha) \gamma / \lambda-1} \alpha^{(1-\alpha) \gamma / \lambda}$ of workers at any skill level $g$ are specialized in knowledge production.

${ }^{13}$ Note that we do not characterize equilibria for $\alpha<\bar{e}$. This is because the analytics become untractable. Results from a similar partial equilibrium model, however, suggest that for $\alpha<\bar{e}$ workers buy knowledge from less able people
} 
(iii) The knowledge assignment function $b^{*}(g)$ is given by

$$
b^{*}(g)=\left(B e^{\lambda g}\right)^{\frac{1}{1-\alpha}} s^{-\frac{\lambda}{\gamma(1-\alpha)^{2}}}
$$

(iv) The human capital of an agent with ability $g$ is

$$
b(g)=\left(B e^{\lambda g}\right)^{\frac{1}{1-\alpha}} s^{-\frac{\lambda \alpha}{\gamma(1-\alpha)^{2}}}
$$

(v) Over the interval $\left[b\left(g_{i}\right), b\left(g_{i+1}\right)\right]$ wages are given by

$$
\omega(b)=\varpi_{i}+A k^{i}\left(b-b\left(g_{i}\right)\right)
$$

where $\omega_{i}=A k^{i}, \varpi_{i}$ can be recursively computed as

$$
\begin{aligned}
\varpi_{i+1} & =\varpi_{i}+A k^{i}\left(b\left(g_{i+1}\right)-b\left(g_{i}\right)\right) ; \\
\varpi_{0} & =A b(0),
\end{aligned}
$$

and where

$$
k=\alpha s^{\frac{\lambda}{\gamma(1-\alpha)}-1}>1 .
$$

PROOF - See Appendix.

Regime II holds if $\gamma(1-\alpha) / \lambda>1$ and $s \in\left[0, \alpha^{\frac{\gamma(1-\alpha)}{\gamma(1-\alpha)-\lambda}}\right.$. Hence it tends to prevail for more efficient information technologies than regime I. As $s$ becomes low, the agents of an economy in regime I try to buy knowledge from workers with an ever greater quality relative to themselves, and eventually bump into a supply constraint for quality workers. ${ }^{14}$ This pushes up the

\footnotetext{
${ }^{14}$ This sentence is only valid in the case of interest where $\gamma(1-\alpha) / \lambda>1$. Otherwise, regime II never arises even for arbitrarily small values of $s$. The reason is as follows. As $s$ falls, there is a race between two effects. First, people attempt to buy knowledge from higher quality workers, who are scarcer. Second, they need to purchase knowledge from fewer people. If $\gamma(1-\alpha) / \lambda<1$, then the second effect dominates, so that there are always more than enough workers of a given quality to match the demand for knowledge suppliers at this quality. Consequently, the economy remains in regime I throughout as $s$ falls to zero.
} 
marginal price of human capital for high quality workers, so that the economy must now be in a regime where the wage schedule is no longer linear.

Proposition 2 tells us that the economy then organizes itself into a "knowledge chain", i.e. a sequence of adjacent intervals of skill levels such that in any interval each worker buys knowledge from a previous generation's worker of the next interval and sells it to a worker of the next generation in the preceding interval, while workers at the lowest interval of skills $\left[0, g_{1}\right]$ are entirely specialized in output production.

The wage schedule is piece-wise linear and convex, as illustrated on Figure 1; the marginal return to human capital is increasing as one moves up the distribution of skills, i.e. as one's position in the knowledge chain is more remote from direct productive activity. As one moves up one ladder in the knowledge chain the marginal return to human capital increases by a factor $k$, where $k$ is given by (12), and, importantly, greater than one. In the $(g, \omega)$ plane, the wage schedule is piece-wise exponential, i.e., log wages are again piece-wise linear (Figure 1).

Hence the marginal return to human capital goes up as one moves up the distribution of skills. This is because the marginal willingness to pay for knowledge tend to accumulate as one moves up the knowledge chain; i.e. the marginal willingness to pay of a given worker for an improvement in the quality of his knowledge input is proportional to his own marginal return to human capital. If the worker is specialized in knowledge, this marginal return itself reflects the marginal willingness to pay for knowledge quality of workers in the preceding ladder, and so on. This cumulative effect is reflected in the $k^{i}$ factor in (11). $k$ captures the marginal willingness to pay for knowledge quality relative to one's marginal return to human capital.

As is also illustrated on figure 1, the human capital acquisition function $b(g)$ and the knowledge assignment function $b^{*}(g)$ are exponential. People buy knowledge from more skilled workers (by a fixed additive constant), and therefore their human capital is below that of their knowledge supplier (by a fixed multiplicative constant). 
One can define the "knowledge distance" between two different skill levels as the number of intervals between them. This is also clearly equal to the number of generations (or, under our more general interpretation, periods) it takes for knowledge to be transmitted from the interval of the highest level to that of the lowest level.

We are now in a position to use the model to characterize the impact of improvements in information technology. The following proposition characterizes the long-run impact of an improvement in IT, i.e. a fall in $s$, on the distribution of income and human capital.

PROPOSITION 3 -Assume (9) holds. Consider a reduction in s. Then, in the long run steady state:

(i) The distribution of human capital shifts up homothetically.

(ii) Inequality as measured by the relative difference in the marginal return to skill between two consecutive ladders increases.

(iii) $g_{i}$ increases homothetically, implying that each ladder covers a larger segment of the distribution of skills, that the knowledge distance between any two types falls or remains constant, and that the number of workers specialized in output production increases.

(iv) There exists some critical level of $s, s^{+}$, that if $s>s^{+}$then the wages of all worker types increase.

(v) There exists $s^{-}$such that if

$$
s \leq s^{-},
$$

then at the bottom of each ladder $i \geq 1$ there exist worker types who are displaced from segment $i$ to segment $i-1$ (lower knowledge distance from direct production activity), and whose wages fall. However, they would eventually benefit from further improvements in information technology.

PROOF - See Appendix.

Proposition 3 analyses the various effects exerted by an improvement in IT on the long-run distribution of income. These effects are the following. 
More efficient information technologies induce people to buy knowledge from fewer and better quality suppliers. Thus the ability gap between a supplier and a consumer of knowledge goes up, so that each knowledge ladder is wider. Consequently, workers at the bottom of a ladder are displaced to the previous one. On the other hand, there is a greater willingness to pay to improve the quality of one's knowledge supplier, which strengthens the cumulative effects of knowledge demand on the marginal return to human capital at a given ladder. In other words, $k$ goes up, so that inequality among knowledge ladders go up. Finally, as in equilibrium all workers buy knowledge from more able workers, there is a uniform multiplicative shift to the distribution of human capital.

Proposition 3 tells us that if IT are initially not too developed, then in the long run all worker types gain from an improvement in information technology (Figure 2). The greater ease with which they accumulate human capital compensates for possible wage losses at a given level of human capital. This process has limits, however, and for $s$ small enough workers who are displaced to lower levels in the knowledge chain suffer long-run wage losses (Figure 3). Whether one gains or loses depends on whether one is displaced or not, i.e. depends on one's relative position in one's segment. As $s$ goes to zero from $s^{-}$, all worker types who were originally specialized in knowledge production experience a marginal wage loss as they cross the boundary to move to a lower ladder. However, when they are stabilized in the directly productive activity, their income ends up rising without bound, as IT gives them access to ever-better knowledge producers.

The first parts of proposition 3 implies that inequality between segments increases. However, as the knowledge distance between two given types falls, inequality between individuals need not increase. We can use some approximation to say more about the net effect on inequality. Consider inequality between two people in the first segment specialized in pure production. According to Proposition 3 , their income is simply proportional to $e^{\lambda g \frac{1}{1-\alpha}}$. Their relative wage, expressed in logs, is therefore equal to $\lambda \Delta g /(1-\alpha)$, which does 
not depend on $s$. Thus IT does not affect inequality between two workers in the bottom segment. Next, consider two knowledge producers belonging to different ladders. The difference equation (11) can be solved to get ${ }^{15}$

$$
\varpi_{i}=\frac{A B^{\frac{1}{1-\alpha}} s^{-\frac{\lambda \alpha}{\gamma(1-\alpha)^{2}}}}{\alpha-s}\left(\alpha-s^{1-\frac{\lambda}{\gamma(1-\alpha)}}+\left(s^{1-\frac{\lambda}{\gamma(1-\alpha)}}-s\right)\left(\frac{\alpha}{s}\right)^{i}\right)
$$

Assume that our two producers are located at critical points with values of $i$ large enough for the first term in brackets to be dominated in (14). Then, given that their rank $i$ can be obtained from their skill level $g$ using the formula $i=-\gamma g / \ln s$, the relative $\log$ wage of these two workers is $\gamma(1-\ln \alpha / \ln s) \Delta g$. This quantity is clearly increasing when $s$ falls. Therefore, IT clearly increases inequality at the top of the distribution of income. In contrast, if one considers say workers originally located in the two bottom segments, it ends up reducing inequality among these people, as segment 0 gradually absorbs segment $1 .^{16}$

\section{Dynamics}

Interestingly, we can also characterize the dynamics of adjustment toward the steady state, provided we assume that the initial distribution of human capital among the old is homothetic to that of the long-run steady state. That is, we assume that originally the human capital of an old worker with ability $g$ is

$$
b_{0}(g)=Z_{0} e^{\lambda g /(1-\alpha)}
$$

Let us limit ourselves to the most interesting regime, i.e. regime II. We can then prove the following:

\footnotetext{
${ }^{15}$ To solve it, first note that $b\left(g_{i+1}\right)-b\left(g_{i}\right)=B^{\frac{1}{1-\alpha}} s^{-\frac{\lambda i}{\gamma(1-\alpha)}} s^{-\frac{\lambda \alpha}{\gamma(1-\alpha)^{2}}}\left(s^{-\frac{\lambda}{\gamma(1-\alpha)}}-1\right)$, so that (11) can be written as $\varpi_{i+1}=\varpi_{i}+x y^{i}$, with $x=A B^{\frac{1}{1-\alpha}} s^{-\frac{\lambda \alpha}{\gamma(1-\alpha)^{2}}}\left(s^{-\frac{\lambda}{\gamma(1-\alpha)}}-1\right)$, and $y=k s^{-\frac{\lambda}{\gamma(1-\alpha)}}=\alpha / s$. Then look for a solution of the form $\varpi_{i}=\Omega_{0}+\Omega_{1} y^{i}$.

${ }^{16}$ Interestingly, this is what Mishel and Bernstein (1994) tend to find when looking at correlations between wage changes and investment in technology.
} 
PROPOSITION 4 - Assume

$$
s^{1-\frac{\lambda}{\gamma(1-\alpha)}} \leq \alpha
$$

and

$$
Z_{0} \leq\left(\alpha B s^{\lambda / \gamma-1}\right)^{1 /(1-\alpha)}
$$

Then there exists an equilibrium path such that

(i) The knowledge assignment function $g_{t}^{*}(g)$, which gives the skill level of the (old) agent supplying knowledge to a (young) agent at date $t \geq 0$ is constant and equal to

$$
g_{t}^{*}(g)=g+\frac{1}{\gamma} \ln \frac{1}{s}
$$

(ii) There exists a sequence of critical ability levels $\left(g_{0}, g_{1}, \ldots ., g_{i}, \ldots.\right)$ such that at any date $t$

a. $g_{i}=-i / \gamma \ln s$, implying $g_{0}=0$.

b. people such that $0 \leq g \leq g_{1}$ are entirely specialized in the production of physical output

c. people such that $g_{i} \leq g \leq g_{i+1}$ are entirely specialized in knowledge production. They sell knowledge to workers in $\left[g_{i-1}, g_{i}\right]$ and buy it from workers in $\left[g_{i+1}, g_{i+2}\right]$

(iii) The human capital of an old agent with ability $g$ at date $t$ is

$$
b_{t}(g)=Z_{t} e^{\lambda g /(1-\alpha)}
$$

where $Z_{t}$ evolves according to

$$
Z_{t+1}=B Z_{t}^{\alpha}\left(\frac{1}{s}\right)^{\frac{\lambda \alpha}{\gamma(1-\alpha)}}
$$


(iv) The knowledge assignment function at $t, b_{t}^{*}(g)$ is therefore

$$
b_{t}^{*}(g)=Z_{t} e^{\lambda g /(1-\alpha)}\left(\frac{1}{s}\right)^{\frac{\lambda}{\gamma(1-\alpha)}}
$$

(v) Over the interval $\left[b\left(g_{i}\right), b\left(g_{i+1}\right)\right]$ wages at date $t$ are given by

$$
\omega_{t}(b)=\varpi_{t i}+\Omega_{i t}\left(b-b_{t}\left(g_{i}\right)\right),
$$

where

$$
\Omega_{i t}=A\left(\alpha B s^{\lambda / \gamma-1}\right)^{i} \prod_{j=0}^{i-1} Z_{t+j}^{\alpha-1}
$$

and $\varpi_{i t}$ can be recursively computed as

$$
\begin{aligned}
\varpi_{i+1, t} & =\varpi_{i t}+\Omega_{i t}\left(b_{t}\left(g_{i+1}\right)-b_{t}\left(g_{i}\right)\right) ; \\
\varpi_{0 t} & =A b(0) .
\end{aligned}
$$

PROOF - See Appendix.

One can check that this equilibrium converges indeed to the steady state derived in the previous subsection. This convergence is gradual and the knowledge ladders are the same at each date, while the distribution of human capital converges homothetically to its long-run level. Equation (20), which gives us the marginal return to human capital in ladder $i$, is interesting. It tells us that it is forward looking down into the future up to a number of periods precisely equal to the knowledge distance between that ladder and output producers. The marginal return to human capital for output producers in generation $t$ (ladder 0 ) is equal to $A$, it then determines their demand for knowledge, and thus the marginal return of those who supply them with knowledge (ladder 1 in generation $t-1$ ), which in turn determines the marginal return to human capital of ladder 2 in generation $t-2$, and 
so one. The price of human capital is forward looking, more so when one is more remote from its ultimate use in the knowledge chain.

This proposition is particularly useful to analyze the dynamic response of the distribution of income to an improvement in information technology, i.e. a fall in $s$, because for any given initial value of $s$ the long-run distribution of human capital as determined by (10) has the assumed functional form for Proposition 4 to apply. Furthermore, the initial value of $Z, Z_{0}$, is given by $B^{1 /(1-\alpha)} s^{-\frac{\lambda \alpha}{\gamma(1-\alpha)^{2}}}$, which satisfies (17) as long as the initial value of $s$ satisfies (9). One can then apply proposition 4 to a fall in $s$, getting the following results:

\section{PROPOSITION 5 -}

(i) The income of the initially old workers who move from segment 1 to segment 0 is unambiguously lower. Consequently, a reduction in $s$ cannot be Pareto-improving.

(ii) Along the adjustment path, the distribution of human capital increases homothetically. That is, $Z_{t}$ is rising along the adjustment path, converging from below to its new long-run value.

(iii) inequality between two consecutive ladders, as measured by the relative difference in the marginal return to human capital, falls with time, converging from above to $k$ as defined by (12)

(iv) That same measure is falling when one moves up the knowledge chain.

PROOF- See Appendix

The first part of Proposition 5 tells us that the impact effect of the improvements in information technology hurts some of the old in the initial generation, namely those who are displaced from ladder 1 to output production. It could also potentially hurt some of the old displaced from one ladder to a lower ladder but who remain specialized in knowledge. Proposition 3 had shown that in the long run, if $s$ is not too low, even displaced worker types gain, because their displacement is compensated by a higher level of human capital. However, this is not true of the initial generation of old workers, 
whose human capital is fixed by their past knowledge acquisition decision, which took place prior to the improvement in information technology.

Part (iii) and (iv) characterize the dynamics of income distribution along the adjustment path. Part (iii) implies that inequality overshoots its longrun level. This is because the improvement in IT boosts the demand for knowledge supplied by highly capable people, while the supply response (i.e. the shift in the distribution of $b$ ) is only gradual. Part (iv) implies that such overshooting is weaker when one moves up the knowledge chain. This is because more skilled workers are at a greater knowledge distance from output producers, so that their wage reflects the expected marginal return to human capital of generations more remote in the future (as implied by (20)) . This quantity is smaller, relative to its long-run value, because human capital is more abundant, i.e. closer to its long run value, for future generations (as implied by (ii)).

\section{Extensions}

In this section we briefly indicate how the model can be extended to make it more realistic.

\subsection{Elastic demand for knowledge}

A first aspect is that the demand for knowledge producers is by construction totally inelastic and always equal to $s$. As a result a fall in $s$ always reduces the number of knowledge producers. In practice this may not happen because as knowledge is cheaper some people who previously did not buy it may start doing so. Empirically, several studies document the rise in the proportion of nonproduction workers. ${ }^{17}$

Therefore, the model's realism is improved if one introduces some elasticity in the demand for knowledge. To do so, we extend the model by assuming that workers have the option of not buying it at all, in which case their re-

\footnotetext{
${ }^{17}$ See Berman et al. (1994) and other references mentioned in the introduction.
} 
sulting human capital is $C e^{\lambda g}$, where $C$ is a constant. For $C$ high enough some workers prefer not to buy human capital. One can then show (see Appendix) that in both regimes I and II, these will be the least able in society, i.e. workers such that $g<g_{0}$, where $g_{0}>0$. Furthermore, $d g_{0} / d s>0$, implying that the total number of knowledge consumers increases when IT improves. Therefore, the net effect on the number of knowledge producers may be either positive or negative. In regime II, this depends on the sign of $d g_{1} / d s$, i.e. on whether the increase in the length of each knowledge segment is larger or smaller than the fall in $g_{0}$. We can prove that as long as $g_{0}$ is strictly positive, $d g_{1} / d s>0$. This implies that the total number of knowledge producers, i.e. the number of people with ability above $g_{1}$, actually increases when $s$ falls, and that rather than having people displaced from the bottom of ladder 1 to the top of the output producing segment, the reverse occurs. However, for large enough knowledge distances $i$ from ladder 0, displacement to the preceding segment does occur, since the effect of the increase in the length of each segment, $\frac{1}{\gamma} \ln \frac{1}{s}$, is multiplied by $i$.

As $s$ becomes small enough, $g_{0}$ is eventually equal to zero, and the previous section's analysis applies: further improvements in IT reduce the number of knowledge producers and workers at the bottom of each ladder are displaced to the preceding ladder. The demand for knowledge has become inelastic as the whole population has been included in the "knowledge economy". 18

\subsection{Growth}

Another possible extension of the model is to introduce exogenous growth in the total factor productivity parameter $A$. It is not difficult to extent our proofs and computations while assuming that $A$ grows at rate $x$, population at rate $n$, and that the interest rate is $r$. The results must then be modified

\footnotetext{
${ }^{18}$ These dynamics are similar to what happens to other new technologies such as consumer appliances while their diffusion from the top to the bottom of the distribution of income is completed.
} 
as follows:

1. In proposition 1 , the indifference regime now holds for $s^{1-\frac{\lambda}{\gamma(1-\alpha)}} \geq$ $\alpha(1+x) /(1+r)$ and $s \leq \alpha(1+x) /(1+r)$. An increase in TFP growth makes this regime therefore less likely than the full specialization regime. Furthermore,

$$
b^{*}(g)=\left(\frac{\alpha B e^{\lambda g}}{s} \frac{1+x}{1+r}\right)^{\frac{1}{1-\alpha}}
$$

and

$$
b(g)=B^{\frac{1}{1-\alpha}}\left(\frac{\alpha}{s} \frac{1+x}{1+r}\right)^{\frac{\alpha}{1-\alpha}} e^{\frac{\lambda g}{1-\alpha}} .
$$

People demand and acquire more human capital when growth is faster.

2. In proposition 2, we now have $g_{t}^{*}(g)=g+\frac{1}{\gamma} \ln \frac{1}{s(1+n)}$ and $g_{i}=$ $-i / \gamma \ln [s(1+n)]$. Faster population growth reduces the length of a knowledge segment, i.e. increases the number of segments. ${ }^{19}$ Furthermore,

$$
k=\alpha s^{\frac{\lambda}{\gamma(1-\alpha)}}-1 \frac{(1+x)(1+n)^{\frac{\lambda}{\gamma(1-\alpha)}}}{1+r}
$$

,implying that when either population or TFP grows more quickly, the return to human capital increases by more when one moves up a knowledge ladder. Finally,

$$
b^{*}(g)=\left(B e^{\lambda g}\right)^{\frac{1}{1-\alpha}} s^{-\frac{\lambda}{\gamma(1-\alpha)^{2}}}(1+n)^{-1 /(1-\alpha)}
$$

and

$$
b(g)=\left(B e^{\lambda g}\right)^{\frac{1}{1-\alpha}} s^{-\frac{\lambda \alpha}{\gamma(1-\alpha)^{2}}}(1+n)^{-\alpha /(1-\alpha)},
$$

\footnotetext{
${ }^{19}$ We now need to assume $s<1 /(1+n)$, as the ratio being old and young is $1 /(1+n)$, and each young needs to learn from $s$ old.
} 
implying that TFP growth does not affect the distribution of human capital, while population growth reduces it homothetically.

These results are not difficult to understand. TFP growth does not affect the balance between the supply and demand of knowledge in terms of people, but makes it more valuable to increase the quality of one's knowledge supplier, since it increases the marginal return to human capital tomorrow relative to its cost today. As a result, the premium to quality increases, which makes it more likely that some workers entirely specialize in knowledge production and, in that regime, increases inequality between knowledge segments (i.e., $k$ ). In regime I, society acquires more human capital by buying it from more qualified workers. In regime II, this is not possible as all high quality workers are already entirely specialized. This attempt is instead reflected in the wage schedule, which becomes steeper and more convex.

As for population growth, by making the old scarcer, it increases the demand of knowledge relative to its supply, thus forcing each agent to buy knowledge from a lower quality supplier. In regime I, this drives people out of the direct production activity into knowledge production. In regime II, this increases the number of people who specialize in knowledge while increasing the number of segments and the marginal willingness to pay for quality.. Thus the resulting distribution of human capital is worsened, while society is both more segmented and more unequal. These effects of population growth come from the fact that knowledge is transmitted from old to young, and would be changed if the timing of knowledge transmission were different.

\section{Concluding remarks}

This paper has developed a theory of the distribution of income, and of the assignment of workers between output and knowledge production, in a world where knowledge is a quality good entering as an input in the production of human capital. The model allows to analyze the effect of an improvement in information technology, i.e. a reduction in the required working time input 
in the production of human capital, on the distribution of income and the occupational pattern.

The central result of this paper is that the impact of an improvement in information technologies on a given worker's income depends on this worker's position relative to his or her 'peer group' of other workers in the same knowledge ladder. Those who are potentially harmed are found at the bottom of each ladder, but these are people at intermediate and high income levels. Workers at the bottom of the distribution of income gain, as they are consumers rather than producers of intangible goods. If this paper message's is to be believed, while information technology may have contributed to the observed overall increase in inequality, one should find other culprits for what has happened at the low end of the distribution of income. 


\section{APPENDIX}

\section{PROOFS}

PROOF of Proposition 1 - If $\omega(b)=A b$ throughout, then the young's optimization problem is concave and the first-order condition (5) is necessary and sufficient. It is easy to check that it is equivalent to (7), which proves (iv). Substituting (7) into (2) proves the first part of (v), while substituting (8) into the density of $g$ proves its second part. Then, applying (3) yields (iii).

To complete the proof, we have to show that this is indeed an equilibrium, i.e. that the supply of old workers in any given interval is actually larger than the demand for knowledge producers coming from the corresponding young workers. There are $\gamma e^{-\gamma g} d g$ young workers between $g$ and $g+d g$. They buy knowledge from $s \gamma e^{-\gamma g} d g$ old agents. Their ability must lie between $g^{*}(g)$ and $g^{*}(g)+g^{* \prime}(g) d g$. Using (iii), we see that the total supply of such workers is $\gamma e^{-\gamma g}\left(\frac{\alpha}{s}\right)^{-\frac{\gamma(1-\alpha)}{\lambda}}$. It will be greater than the demand for knowledge producers of that ability range if and only if

$$
s \gamma e^{-\gamma g} \leq \gamma e^{-\gamma g}\left(\frac{\alpha}{s}\right)^{-\frac{\gamma(1-\alpha)}{\lambda}},
$$

which is clearly equivalent to (6).

Finally, one has to check that $b^{*}(0) \geq b_{0}$, i.e. that the knowledge supplier of the lowest ability is indeed available on the market. This is equivalent to

$$
\left(\frac{\alpha B}{s}\right)^{\frac{1}{1-\alpha}} \geq B^{\frac{1}{1-\alpha}}\left(\frac{\alpha}{s}\right)^{\frac{\alpha}{1-\alpha}}
$$

i.e.

$$
\alpha \geq s
$$

Conversely, it is straightforward to check that if all these conditions hold, one indeed has an equilibrium. Q.E.D. 
PROOF of proposition 2 - Let us start from the knowledge assignment function in (i) and show that it is supported by a competitive equilibrium which satisfies (ii)-(v). First, note that in such an equilibrium the supply of knowledge produced by any type $g^{*}$ matches the demand coming from the corresponding type $g$. To see this, note that there are $\gamma e^{-\gamma g} d g$ workers between $g$ and $g+d g$, and that these workers buy knowledge from $s \gamma e^{-\gamma g} d g$ suppliers. They buy it from workers between $g^{*}(g)$ and $g^{*}(g+d g)$, and there are $\gamma e^{-\gamma g^{*}} g^{* \prime}(g) d g$ such workers. Using the definition of $g^{*}(g)$ it is easy to see that this is exactly equal to $s \gamma e^{-\gamma g} d g$. Thus, all workers above $g^{*}(0)=g_{1}=-(\ln s) / \gamma$ are entirely specialized in knowledge, while those below $g_{1}$ produce output.

Next, we show that this allocation of resources is the outcome of individual optimization if wages are determined by $(\mathrm{v})$ and if human capital is related to skills by (iv) (which implies, along with (i), that (iii) holds).

People elect the human capital level of their knowledge supplier $b^{*}$ by maximizing

$$
\max _{b^{*}} \omega\left(B e^{\lambda g} b^{* \alpha}\right)-s \omega\left(b^{*}\right)
$$

Our first step is to show that $b^{*}(g)$ satisfies the first-order conditions, i.e. that it is a local optimum. To see this, first note that if $g \in\left[g_{i}, g_{i+1}\right]$, then $b^{*}(g) \in\left[b\left(g_{i+1}\right), b\left(g_{i+2}\right)\right]$. To satisfy the first-order condition it must maximize $A k^{i} B e^{\lambda g} b^{* \alpha}-s A k^{i+1} b^{*}$, implying that the F.O.C is

$$
\alpha B e^{\lambda g} b^{* \alpha-1}-s k=0
$$

This is equivalent to

$$
b^{*}(g)=\left(\frac{\alpha B e^{\lambda g}}{s k}\right)^{\frac{1}{1-\alpha}},
$$

which, given the definition of $k$, is equivalent to (iii).

In the special case where $g=g_{i}$, the objective function is not differentiable, and one has a local optimum if and only if the right-derivative (resp. left-derivative) is negative (resp. positive) or zero. These two conditions are 


$$
A k^{i+1} \alpha B e^{\lambda g} b^{* \alpha-1}-s k^{i+2} \leq 0,
$$

and

$$
A k^{i} \alpha B e^{\lambda g} b^{* \alpha-1}-s k^{i+1} \geq 0 .
$$

Together, these two conditions are equivalent to (23).

Next, we prove that this is a global optimum. Given the convexity of the wage schedule and its linearity within each interval $\left[b\left(g_{i}\right), b\left(g_{i+1}\right)\right]$ it is clearly an optimum among all the values of $b^{*}$ such that the resulting human capital of the individual with ability $g$ remains within $\left[b\left(g_{i}\right), b\left(g_{i+1}\right)\right]$. This is because over that interval the first term in (22) is linear in its argument, so that the objective function is concave.

Consider now what happens if individual $g$ tries to get a level of human capital $\tilde{b}$ in the $\left[b\left(g_{i+1}\right), b\left(g_{i+2}\right)\right]$ interval. Under our assumed knowledge assignment function, individual $g_{i+1}$ buys knowledge from individual $g_{i+2}$, which gives him a level of human capital equal to $b\left(g_{i+1}\right)$. Given that $g<g_{i+1}$, in order to get the desired level of human capital, individual $g$ must buy knowledge from some $g^{\prime}>g_{i+2}$, i.e. from some $b^{\prime}>b\left(g_{i+2}\right)$. Consequently, to get a marginal wage equal to $A k^{i+1}$, individual $g$ must pay a marginal wage at least equal to $A k^{i+2}$, i.e. equal to $A k^{m}$, with $m \geq i+2$. Given that $b^{\prime}>b^{*}(g)$, it must be the case that $\alpha A k^{i+1} B e^{\lambda g} b^{\prime \alpha-1}-s A k^{m}<0$ for all $b^{\prime}$ such that $\tilde{b} \in\left[b\left(g_{i+1}\right), b\left(g_{i+2}\right)\right]$, which implies (by continuity and convexity of the wage schedule) that the best individual $g$ can do is to pick up $\tilde{b}=b\left(g_{i+1}\right)$. But since $b\left(g_{i+1}\right) \in\left[b\left(g_{i}\right), b\left(g_{i+1}\right)\right]$ and since $b^{*}(g)$ maximizes $g$ 's welfare for the resulting $b$ in $\left[b\left(g_{i}\right), b\left(g_{i+1}\right)\right]$, this clearly generates less utility than picking $b^{*}(g)$.

This argument can be extended by induction as follows: to reach some $\tilde{b}$ in $\left[b\left(g_{j+1}\right), b\left(g_{j+2}\right)\right], j \geq i$, individual $g$ must buy human capital from an agent with human capital greater than $b\left(g_{j+2}\right)$, implying that the marginal 
wage he pays is greater than the one he gets by a factor at least as large as $k$. This implies again that the optimum in that interval is $\tilde{b}=b\left(g_{j+1}\right)$, which yields a utility no greater than the optimum in the preceding interval $\left[b\left(g_{j}\right), b\left(g_{j+1}\right)\right]$. Thus, by induction, all these optima are inferior to the one where the agent picks $b^{*}(g)$.

A similar induction argument can be made with respect to vales of $\tilde{b}$ in inferior intervals.

Therefore, given this knowledge assignment function and this wage schedule, it is indeed optimal for each $g$ to buy knowledge from $b^{*}(g)$. This in turn validates (iii) and (iv), while the wage schedule implies the specialization pattern in (ii). Therefore, we do have an equilibrium. Q.E.D.

PROOF of proposition 3 - (i), (ii), and (iii) follow directly from proposition 2. Let us now prove (iv). Consider a fall in $s$ from $s_{O}$ to $s_{N}<s_{O}$, where $s_{N}$ is arbitrarily close to $s_{O}$. Let us assume (9) holds. To prove that all worker types gain, we prove that the new critical types $g_{i}$ all gain. Because the wage schedule is piece-wise linear and convex in $e^{\lambda g /(1-\alpha)}$, it is enough to prove that its kinks are all above its previous location to prove that it shifts up everywhere (otherwise convexity would be violated). Thus, we have to prove that

$$
\varpi_{i N} \geq \varpi_{i O}+A k_{0}^{i}\left[b_{O}\left(g_{i N}\right)-b_{i O}\right],
$$

where subscript $O$ (resp. $N$ ) refers to variables and functions corresponding to $s=s_{O}$ (resp. $\left.s=s_{N}\right)$, and $b_{i O}=b_{O}\left(g_{i O}\right)$. This formula says that the new wage at kink $i$ must be greater than the wage of the same type in the old wage schedule (where this type was in the interior of ladder $i$ ).

We prove this inequality by induction. First, note that it is trivially satisfied for $i=0$. Next, assume that it is satisfied for $i$. We would like to show that it is then satisfied for $i+1$, i.e. that

$$
\varpi_{i+1, N} \geq \varpi_{i+1, O}+A k_{O}^{i+1}\left[b_{O}\left(g_{i+1, N}\right)-b_{i+1, O}\right]
$$


Using the recursive law (11), we see that this is equivalent to

$\varpi_{i N}+A k_{N}^{i}\left[b_{i+1, N}-b_{i N}\right] \geq \varpi_{i O}+A k_{O}^{i}\left[b_{i+1, O}-b_{i O}\right]+A k_{O}^{i+1}\left[b_{O}\left(g_{i+1, N}\right)-b_{i+1, O}\right]$,

If (24) holds, then a sufficient condition for (25) to hold is

$$
\begin{aligned}
A k_{N}^{i}\left[b_{i+1, N}-b_{i N}\right] \geq & A k_{O}^{i}\left[b_{i+1, O}-b_{i O}\right] \\
& +A k_{O}^{i+1}\left[b_{O}\left(g_{i+1, N}\right)-b_{i+1, O}\right]-A k_{0}^{i}\left[b_{O}\left(g_{i N}\right)-b_{i O}\right] \\
= & A k_{O}^{i}\left[b_{i+1, O}-b_{O}\left(g_{i N}\right)\right]+A k_{O}^{i+1}\left[b_{O}\left(g_{i+1, N}\right)-b_{i+1, O}\right]
\end{aligned}
$$

Using the formulae of proposition 2 and assuming that $s_{N}=s_{O}(1-\mu)$, with $\mu \ll 1$, we get that this is equivalent to ${ }^{20}$

$$
i\left(s^{-\frac{\lambda}{\gamma(1-\alpha)}}-1-\frac{\alpha \lambda}{\gamma(1-\alpha)} s^{-1}+\frac{\lambda}{\gamma(1-\alpha)}\right)+\frac{\lambda}{\gamma(1-\alpha)^{2}}\left(s^{-\frac{\lambda}{\gamma(1-\alpha)}}-\alpha\right) \geq 0 .
$$

This will hold for all $i \geq 0$ if the term in bracket is always positive as well as the sum of all the other terms. For the term in brackets, this is equivalent to

$$
s^{1-\frac{\lambda}{\gamma(1-\alpha)}} \geq s\left(1-\frac{\lambda}{\gamma(1-\alpha)}\right)+\frac{\alpha \lambda}{\gamma(1-\alpha)}
$$

Note that (9) implies $\frac{\lambda}{\gamma(1-\alpha)}<1$, so that the RHS is a linear combination between $s$ and $\alpha$. Note also that the LHS is increasing and concave in $s$, so that this defines a (possibly empty) interval $\left[s_{0}, s_{1}\right]$, with $0<s_{0}<s_{1}<\infty$.

\footnotetext{
${ }^{20}$ This is done by expressing each new variable as a function of the corresponding old one, as well as $\mu$, substituting into (25), and ignoring any second-order terms in $\mu$. Thus we have:

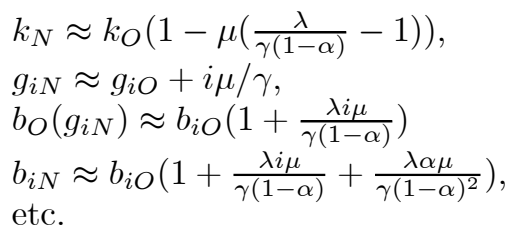


Next, note that for $s=\alpha^{\frac{1}{1-\frac{\lambda}{\gamma(1-\alpha)}}}<\alpha$ it holds since the LHS is equal to $\alpha$ and the RHS is smaller than $\alpha .{ }^{21}$ Therefore, $s_{0}<\alpha^{\frac{1}{1-\frac{\lambda}{\gamma(1-\alpha)}}}<s_{1}$ and this inequality holds over some interval of values of $s$ greater than zero but smaller than the maximum for which (9) holds, $\alpha^{\frac{1}{1-\frac{\lambda}{\gamma(1-\alpha)}}}$. Let $\left[s^{+}, \alpha^{\frac{1}{1-\frac{\lambda}{\gamma(1-\alpha)}}}\right]$ be such an interval. In this interval, one has $\left(s^{-\frac{\lambda}{\gamma(1-\alpha)}}-1-\frac{\alpha \lambda}{\gamma(1-\alpha)} s^{-1}+\frac{\lambda}{\gamma(1-\alpha)}\right)>0$. Turning now to the last term $\left(s^{-\frac{\lambda}{\gamma(1-\alpha)}}-\alpha\right)$, it is always positive as $s<1$. Consequently, (26) holds for $s \in\left[s^{+}, \alpha^{\frac{1}{1-\frac{\lambda}{\gamma(1-\alpha)}}}\right]$.

This completes the proof of (iv). Let us now prove (v). We first consider the wage of agent $g_{1 N}$, who defines the first kink in the new wage schedule. His wage is simply equal to

$$
\begin{aligned}
\omega_{N}\left(b_{1 N}\right) & =\varpi_{1 N}=A b_{1 N} \\
& =A B^{\frac{1}{1-\alpha}} s_{N}^{-\frac{\lambda}{\gamma(1-\alpha)^{2}}} .
\end{aligned}
$$

His wage prior to the fall in $s$ can be computed using the relevant formula for ladder 1 :

$$
\begin{aligned}
& \omega_{O}\left(b_{1}\right)=\varpi_{1 O}+A k_{O}\left[b_{O}\left(g_{1 N}\right)-b_{1 O}\right] \\
& =A B^{\frac{1}{1-\alpha}} s_{O}^{-\frac{\lambda}{\gamma(1-\alpha)^{2}}}+A \alpha s_{O}^{\frac{\lambda}{\gamma(1-\alpha)}-1}\left[B^{\frac{1}{1-\alpha}} s_{O}^{-\frac{\lambda \alpha}{\gamma(1-\alpha)^{2}}} s_{N}^{-\frac{\lambda}{\gamma(1-\alpha)}}-B^{\frac{1}{1-\alpha}} s_{O}^{-\frac{\lambda}{\gamma(1-\alpha)^{2}}}\right] \text {. }
\end{aligned}
$$

Comparing this with (27), we see that the wage of this type of worker will increase if and only if

$$
\frac{s_{N}^{-\frac{\lambda}{\gamma(1-\alpha)^{2}}}-s_{O}^{-\frac{\lambda}{\gamma(1-\alpha)^{2}}}}{s_{N}^{-\frac{\lambda}{\gamma(1-\alpha)}}-s_{O}^{-\frac{\lambda}{\gamma(1-\alpha)}}} \geq \alpha s_{O}^{\frac{\lambda(1-2 \alpha)}{\gamma(1-\alpha)^{2}}-1} .
$$

Using again $s_{N}=s_{O}(1-\mu)$, with $\mu \ll 1$ we get that this is equivalent to

$$
s_{O}^{1-\frac{\lambda}{\gamma(1-\alpha)}} \geq \alpha(1-\alpha)
$$

${ }^{21}$ Remember that $\alpha^{\frac{1}{1-\frac{\lambda}{\gamma(1-\alpha)}}}$ is the highest possible value of $s$ for which (9) holds. 
Consequently, if this inequality is violated, meaning that $s_{O}$ is too small, then the wages of this type of agent falls.

To prove that the wages of agents displaced from higher segments also fall for $s$ small enough, one can just replicate the above proof by induction, inverting signs. The preceding condition guarantees that the induction process can be initiated. It can be unraveled provided the LHS of (26) is negative for any $i$. This will work provided $s<s^{+}$, which guarantees that the first term in brackets in (26) is negative, and if the LHS of (26) is negative at $i=1$, or equivalently

$$
s^{1-\frac{\lambda}{\gamma(1-\alpha)}}\left(1+\frac{\lambda}{\gamma(1-\alpha)^{2}}\right)+s \frac{\lambda(1-2 \alpha)}{\gamma(1-\alpha)^{2}}<s+\frac{\alpha \lambda}{\gamma(1-\alpha)} .
$$

Given that $\frac{\lambda}{\gamma(1-\alpha)}<1$, this always holds provided $s$ is lower than some $s_{2}$. Thus (v) holds for $s \leq s^{-}=\min \left(s_{2}, s^{+},[\alpha(1-\alpha)]^{\frac{\gamma(1-\alpha)}{\gamma(1-\alpha)-\lambda}}\right)$.

Finally, to prove that wages eventually rise, note that any fixed worker type $g$ ends up in the directly productive activity as $s$ goes to zero, and that his human capital $b(g)$ then goes to infinity, as does his wage $A b$. Q.E.D.

PROOF of proposition 4 - We want to construct an equilibrium path such that the segments are constant and equal to their long-run level as determined by proposition 2 . First, note that the knowledge assignment function $g^{*}(g)$ realizes equality of supply and demand for each type of knowledge producer at any date. Furthermore, if it applies, it necessarily implies (ii). What is the implied evolution of human capital? If at date $t$ it is given by (18), then using $g^{*}(g)$ and our human capital production function (2), it is easy to see that at $t+1$ it is determined by (18) with $t$ replaced with $t+1$ and $Z_{t+1}$ as defined by (19). This proves (iii), which trivially implies (iv). Next, note that if $\omega_{t}$ is the wage schedule at $t$, then a young at date $t$ elects the human capital of his knowledge supplier $b^{*}$ by maximizing

$$
\omega_{t+1}\left(B e^{\lambda g} b^{* \alpha}\right)-s \omega_{t}\left(b^{*}\right)
$$


The first-order condition is equivalent to

$$
\frac{\omega_{t}^{\prime}\left(b_{t}^{*}(g)\right)}{\omega_{t+1}^{\prime}\left(b_{t+1}(g)\right)}=\alpha B e^{\lambda g} b_{t}^{*}(g)^{\alpha-1} s^{-1}
$$

However, under our candidate equilibrium path we have

$$
b_{t}^{*}(g)=b_{t}\left(g^{*}(g)\right)=Z_{t} e^{\frac{\lambda g}{1-\alpha}} s^{-\frac{\lambda}{\gamma(1-\alpha)}} .
$$

Plugging this into the preceding formula we get

$$
\frac{\omega_{t}^{\prime}\left(b_{t}^{*}(g)\right)}{\omega_{t+1}^{\prime}\left(b_{t+1}(g)\right)}=\alpha B Z_{t}^{\alpha-1} s^{\lambda / \gamma-1} \text {. }
$$

Given that $g$ belongs to the segment preceding that of $g^{*}(g)$, one can check that (28) holds if wages are defined by (v). ${ }^{22}$ Furthermore, if (10) and (16) hold, (v) defines a wage schedule which is convex and piece-wise linear. One can then replicate the induction argument of the proof of proposition 2 to show that such a wage schedule implies that $b^{*}(g)$ is not only a local optimum but also a global one. Finally, given that wages in the first segment are $A b$ and that they are superior to $A b$ for higher ladders, this wage schedule trivially induces the right specialization. Therefore, we have proved that the assignment function defined in (i) along with the wage schedule defined in (v) indeed support an equilibrium path along which (ii),(iii) and (iv) are satisfied. Q.E.D.

NB - To construct the wage schedule using the necessary condition (28) one can simply work by backward induction starting from the marginal wage of ladder 0 at an arbitrary time $s$. It must be equal to $A$. (28) applied to $t=s-1$ then allows to compute the marginal wage of ladder 1 at $s-1$. Applying it again to $t=s-2$ we can then recover the marginal wage of ladder 2 at $t=s-2$, and so forth. This process yields (20).

\footnotetext{
${ }^{22}$ More precisely:
}

$$
\frac{\omega_{t}^{\prime}\left(b_{t}^{*}(g)\right)}{\omega_{t+1}^{\prime}\left(b_{t+1}(g)\right)}=\frac{A\left(\alpha B s^{\lambda / \gamma-1}\right)^{i+1} Z_{t}^{\alpha-1} \ldots Z_{t+i}^{\alpha-1}}{A\left(\alpha B s^{\lambda / \gamma-1}\right)^{i} Z_{t+1}^{\alpha-1} \ldots Z_{t+i}^{\alpha-1}}
$$


PROOF of Proposition 5 - To prove (i), just note that the income of a worker with human capital $b$ in segment 1 is strictly greater than $A b$, while it is exactly equal to $A b$ if the same worker were in segment 0 . Next, note that the old of the initial generation have their human capital predetermined, so that they necessarily lose when moving from segment 1 to segment 0 .

Next, note that to characterize adjustment dynamics, we can use proposition 4 , since for any initial value of $s$ the long-run distribution of $b$ has the functional form defined by (15). A fall in $s$ implies that $Z_{t}$ rises monotonically to its new, higher, long-run level along the convergence path. This is an implication of (19) and (10). ${ }^{23}$ Thus, we have proved (i) and (ii). Finally, the relative marginal return to human capital between two consecutive ladders is simply determined by

$$
\frac{\Omega_{i+1, t}}{\Omega_{i t}}=Z_{t+i}^{\alpha-1}\left(\alpha B s^{\lambda / \gamma-1}\right) .
$$

Given that $\alpha<1$ and that $Z_{t}$ increases with $t$, this is clearly falling with both $t$ and $i$, thus proving (iii) and (iv). Q.E.D.

\section{EXTENSION}

\section{Elastic demand for knowledge}

We assume that if someone does not buy knowledge his human capital is $b=C e^{\lambda g}$. It is then not difficult to check that one can construct equilibria similar to the ones derived in propositions 1 and 2 by simply translating them to the right by a distance $g_{0}$ on the $g$ axis, while constructing $g_{0}$ such that people with $g<g_{0}$ do not buy knowledge, with $g_{0}$ being indifferent.

In regime I, the welfare of an agent $g$ who buys knowledge from an agent with human capital $b^{*}(g)$ is given by

$$
\begin{aligned}
u(g) & =A b(g)-A s b^{*}(g) \\
& =A B^{\frac{1}{1-\alpha}} \alpha^{\frac{\alpha}{1-\alpha}} e^{\frac{\lambda g}{1-\alpha}} s^{-\frac{\alpha}{1-\alpha}}(1-\alpha)
\end{aligned}
$$

\footnotetext{
${ }^{23}$ Equation (10) is equivalent to defining the long-run value of $Z$ as $Z_{L R}=$ $B^{\frac{1}{1-\alpha}} s^{-\frac{\lambda \alpha}{\gamma(1-\alpha)^{2}}}$, which is clearly falling with $s$.
} 
This is lower than not buying knowledge at all if and only if

$$
B^{\frac{1}{1-\alpha}} \alpha^{\frac{\alpha}{1-\alpha}} e^{\frac{\lambda g}{1-\alpha}} s^{-\frac{\alpha}{1-\alpha}}(1-\alpha) \leq C e^{\lambda g}
$$

Therefore, non buyers are defined by $g<g_{0}$, with $g_{0}$ determined by

$$
g_{0}=\frac{1}{\lambda} \ln s+\frac{1-\alpha}{\alpha \lambda} \ln \left(C /\left[(1-\alpha) B^{\frac{1}{1-\alpha}} \alpha^{\frac{\alpha}{1-\alpha}}\right]\right)
$$

This may be positive if $C$ large enough and $s$ not too small, and it is clearly increasing in $s$.

One technical detail is that it may not be feasible to buy knowledge from an agent with $b=b^{*}(g)$ because there is a hole in the distribution of $b$ as one passes the $g_{0}$ threshold: $b(g)$ jumps at $g=g_{0}$. However this is not true for $g$ smaller than but close enough to $g_{0}$, since the assumption $\alpha \geq s$ implies $b^{*}(g)>b(g)$. So the formula determining the indifference threshold $g_{0}$ is correct, since people around that level can actually buy their preferred knowledge level $b^{*}(g)$. The only people who could not do so are those for whom $g$ is low enough relative to $g_{0}$. But this further reduces their value of buying knowledge, which is lower than $C e^{\lambda g}$ anyway. So taking into account this difficulty does not alter our conclusions. To prove that we have constructed an equilibrium, just reproduce the proof of prop. 1 .

In regime II, we can construct a similar translated equilibrium, with $g^{*}(g)=g-(\ln s) / \gamma$ for $g \geq g_{0}, g_{i}=g_{0}-i(\ln s) / \gamma$, and where agents with ability $g<g_{0}$ do not buy knowledge. Since people just at the right of $g_{0}$ would buy knowledge from people just at the bottom of segment 1 , a worker with $g=g_{0}$ exactly would buy knowledge from $g=g_{1}$ exactly. Hence for $g<g_{0}$ one would purchase knowledge from agents below $g_{1}$, so that the cost of knowledge is $s A b^{*}$. We construct $g_{0}$ so that it is indifferent about buying knowledge, which is equivalent to

$$
\begin{aligned}
A b\left(g_{0}\right)-A s b^{*}\left(g_{0}\right) & =A B^{\frac{1}{1-\alpha}} e^{\frac{\lambda g_{0}}{1-\alpha}}\left(s^{-\frac{\lambda \alpha}{\gamma(1-\alpha)^{2}}}-s^{1-\frac{\lambda}{\gamma(1-\alpha)^{2}}}\right) \\
& =A C e^{\lambda g_{0}}
\end{aligned}
$$


To prove that all workers with $g>g_{0}$ prefer to acquire knowledge, we show that $d u / d g$ is greater under knowledge acquisition for any $g>g_{0} \cdot{ }^{24}$ If this is true, then, as type $g_{0}$ is indifferent, by integration $u(g)$ will be greater under knowledge acquisition for all $g>g_{0}$. This condition is equivalent to

$$
\omega^{\prime}(b(g)) b^{\prime}(g)-s \omega^{\prime}\left(b^{*}(g)\right) b^{* \prime}(g)>\lambda A C e^{\lambda g}
$$

Using the results of proposition $2^{25}$, we see that this is equivalent to

$$
B^{\frac{1}{1-\alpha}} k^{i} e^{\frac{\lambda \alpha g}{1-\alpha}}\left[s^{-\frac{\lambda \alpha}{\gamma(1-\alpha)^{2}}}-k s^{1-\frac{\lambda}{\gamma(1-\alpha)^{2}}}\right]>(1-\alpha) C
$$

Rearranging, and using the definition of $g_{0}$, we see that this is equivalent to

$$
s^{\frac{\lambda}{\gamma(1-\alpha)}-1}\left[k^{i} e^{\frac{\lambda \alpha g}{1-\alpha}}-(1-\alpha) e^{\frac{\alpha \lambda g_{0}}{1-\alpha}}\right]>k^{i+1} e^{\frac{\lambda \alpha g}{1-\alpha}}-(1-\alpha) e^{\frac{\alpha \lambda g_{0}}{1-\alpha}} .
$$

Plugging in the definition of $k$ and rearranging we get that this is equivalent to

$$
k^{i+1} e^{\lambda \alpha\left(g-g_{0}\right) /(1-\alpha)}>k-\alpha
$$

which is trivially true given that $k>1$ and $g>g_{0}$.

Next, we prove that workers with $g<g_{0}$ prefer not to acquire knowledge. Clearly, they will not acquire more knowledge than type $g_{0}$, i.e. they would buy knowledge from somebody with human capital $b<b^{*}\left(g_{0}\right)=b\left(g_{1}\right)$. Thus they will prefer not to acquire knowledge if for all such $b$ we have

$$
B e^{\lambda g} b^{\alpha}-s b<C e^{\lambda g}
$$

\footnotetext{
${ }^{24}$ It is enough to prove that in all the points where $u$ is differentiable, since $u$ is continuous and is not differentiable only for a countable set of isolated points.

${ }^{25}$ More precisely, using the properties of the translated equilibrium we are constructing, which are the same as in proposition 2 , up to a translation by a distance $1 / \gamma \ln (1 / \bar{e})$.
} 
Let $\tilde{b}(g)$ be the value of $b$ which gives the unconstrained maximum of the LHS, i.e.

$$
\tilde{b}(g)=\left(\frac{\alpha B}{s} e^{\lambda g}\right)^{\frac{1}{1-\alpha}} .
$$

Assume that $\tilde{b}(g)<b^{*}\left(g_{0}\right)$. Then the maximum feasible value of the LHS of (30) is attained at $b=\tilde{b}(g)$. Consequently, it is given by

$$
B^{\frac{1}{1-\alpha}} e^{\lambda g /(1-\alpha)}\left(\frac{\alpha}{s}\right)^{\frac{1}{1-\alpha} \alpha}-B^{\frac{1}{1-\alpha}} e^{\lambda g /(1-\alpha)} s^{-\alpha /(1-\alpha)}(\alpha)^{\frac{1}{1-\alpha}} .
$$

Using this expression and the definition of $g_{0}$, we see that (30) holds if and only if

$$
e^{\alpha \lambda\left(g-g_{0}\right) /(1-\alpha)} s^{-\frac{\alpha}{1-\alpha}} \alpha^{\frac{\alpha}{1-\alpha}}(1-\alpha)<s^{-\frac{\lambda \alpha}{\gamma(1-\alpha)^{2}}}-s^{1-\frac{\lambda}{\gamma(1-\alpha)^{2}}} .
$$

Furthermore, using (31) and the formulas of proposition 2, we see that the inequality $\tilde{b}(g)<b^{*}\left(g_{0}\right)$ is equivalent to

$$
e^{\frac{\alpha \lambda\left(g-g_{0}\right)}{1-\alpha}}<s^{-\frac{\lambda \alpha}{\gamma(1-\alpha)^{2}}} s^{\frac{\alpha}{1-\alpha}} \alpha^{-\frac{\alpha}{1-\alpha}}
$$

Plugging this into the LHS of (32), we see that it holds if

$$
\alpha>s^{1-\frac{\lambda}{\gamma(1-\alpha)}}
$$

which is true since (9) holds.

Next, consider the case where $\tilde{b}(g)>b^{*}\left(g_{0}\right)$. Then the maximum feasible value of the LHS (30) is attained at $b=b^{*}\left(g_{0}\right)$. It is therefore given by

$$
B^{\frac{1}{1-\alpha}}\left(e^{\lambda g} e^{\frac{\lambda \alpha g_{0}}{1-\alpha}} S^{-\frac{\lambda \alpha}{\gamma(1-\alpha)^{2}}}-e^{\frac{\lambda g_{0}}{1-\alpha}} S^{1-\frac{\lambda}{\gamma(1-\alpha)^{2}}}\right)
$$

Using the definition of $g_{0}$, and rearranging, it follows that (30) holds if and only if

$$
0<s^{1-\frac{\lambda}{\gamma(1-\alpha)^{2}}} e^{\frac{\lambda \alpha g_{0}}{1-\alpha}}\left(e^{\lambda g_{0}}-e^{\lambda g}\right)
$$


which always holds since $g_{0}>g$.

This completes the determination of $g_{0}$ and the proof that people buy knowledge if and only if $g \geq g_{0}$. To complete the construction of the equilibrium, one simply uses the same steps as in the proof of proposition 2 where $g_{0}$ is no longer necessarily equal to zero.

Finally, note that for $C>0,(29)$ defines a value of $g_{0}$ which is falling when $s$ falls and eventually becomes negative, in which case we are in the regime of proposition 2 .

To determine whether $g_{1}$ rises or falls with $s$, we differentiate the following expression, using (29):

$$
g_{1}=g_{0}+\frac{1}{\gamma} \ln \frac{1}{s}
$$

We get

$$
\frac{d g_{1}}{d s}=-\frac{1}{\gamma s}+\frac{1-\alpha}{\alpha \lambda} \frac{\frac{\lambda \alpha}{\gamma(1-\alpha)^{2}} s^{-\frac{\lambda \alpha}{\gamma(1-\alpha)^{2}}-1}+\left(1-\frac{\lambda}{\gamma(1-\alpha)^{2}}\right) s^{-\frac{\lambda}{\gamma(1-\alpha)^{2}}}}{s^{-\frac{\lambda \alpha}{\gamma(1-\alpha)^{2}}}-s^{1-\frac{\lambda}{\gamma(1-\alpha)^{2}}}} .
$$

Rearranging we see that we have $d g_{1} / d s \geq 0$ if and only if

$$
\alpha s^{\frac{\lambda}{\gamma(1-\alpha)}-1} \geq \alpha+\frac{1-\alpha}{\alpha}\left(1-\frac{\gamma(1-\alpha)}{\lambda}\right) .
$$

This is true given that in regime II the LHS is greater than 1 and that $\gamma>\lambda$, which in turn implies that the RHS is less than one. This proves the fact that as long as $g_{0}>0$, a fall in $s$ increases the total number of knowledge producers. 


\section{REFERENCES}

Acemoglu, Daron (1999), "Changes in Unemployment and Wage Inequality: An Alternative Theory and Some Evidence", American Economic Review; 89(5), 1259-78.

American Management Association. (2000). 2000 AMA Survey: Staffing and Structure

Autor, David, Lawrence Katz, and Alan Krueger, "Computing Inequality: Have Computers Changed the Labor Market?" Quarterly Journal of Economics; 113(4), 1169-1213.

Beaudry, Paul and David Green (2000), "Wages and employment in the US and Germany: What explains the difference ?", mimeo, U. British Columbia

Berman, Eli, John Bound, and Zvi Griliches (1994), "Changes in the demand for skilled labor within US manufacturing industries: evidence from the Annual Survey of Manufacturing", Quarterly Journal of Economics 109, 367-397

Bewley, Truman (1980), "The optimum quantity of money" in J.H. Kareken and N. Wallace, eds, Models of Monetary Economies, Minneapolis: Federal Reserve Bank of Minneapolis, 169-210.

Bound, John and Johnson, George (1992), "Changes in the Structure of Wages in the 1980's: An Evaluation of Alternative Explanations" American Economic Review; 82(3), 371-92.

Calvo, Guillermo-A. and Stanislaw Wellisz, "Hierarchy, Ability, and Income Distribution", Journal of Political Economy; 87(5), Part 1, Oct. 1979, 991-1010.

Caselli, Francesco (1998), "Technological Revolutions" American Economic Review; 89(1), March 1999, pages 78-102.

Cooke, Sandra D. (2000), "The information technology workforce", IMP Magazine, April; [http://www.cisp.org/imp/april_2000/cooke/04_00cooke.htm] 
Cappelli, Peter (1993) "'Are skill requirements rising? Evidence from production and clerical jobs", Industrial and Labor Relations Review, 51530

DiNardo, John, and Jörn-Steffen Pischke (1997), "The returns to computer use revisited: have pencils changed the wage structure too ?", Quarterly Journal of Economics, 112, 1, 291-304

Doms, Mark, Timothy Dunne, and Kenneth R. Troske (1997), "Workers, Wages and Technology", Quarterly Journal of Economics, 112, 1, 253-290

Entorf, Horst, Michel Gollac, and Francis Kramarz (1999), "New Technologies, Wages, and Worker Selection", Journal of Labor Economics, 17, 3, 1999.

Galor, Oded and Omer Moav (1998), "Ability Biased Technological Transition, Wage Inequality and Growth" Centre for Economic Policy Research Discussion Paper: 1972.

Garicano, Luis (2000), "Hierarchies and the Organization of Knowledge in Production" Journal of Political Economy; 108(5), 874-904.

Gottschalk, Peter and Timothy Smeeding (1997), "Cross-National Comparisons of earnings and Income Inequality", Journal of Economic Literature, 35, 633-687

Howell, David R. (1997) "Institutional failure and the American worker", Jerome Levy Institute Brief \#29

Howell, David R., Margaret Duncan and Bennett Harrison (1998), "Low wages in the US and high unemployment in Europe: A critical assessment of the conventional wisdom", Center of Economic Policy Analysis working paper \#5, 1998.

Krueger, Allan (1993), "Have computers changed the wage structure?", Quarterly Journal of Economics

Krugman, Paul (1994), "Past and Prospective Causes of High Unemployment", in Reducing Unemployment: Current issues and policy options, Federal Reserve Bank of Kansas City, Jackson Hole, 49-80.

Mishel, Lawrence and Jared Bernstein (1994), "Is the technology black 
box empty? An empirical examination of the impact of technology on wage inequality and the employment structure",Economic Policy Institute WP \#217, 1994. [http://www.lights.com/epi/virlib/Technical/1994/isthetechnology.PDF]

Murphy, Kevin M.; Shleifer, Andrei; Vishny, Robert W, "The Allocation of Talent: Implications for Growth" Quarterly Journal of Economics; 106(2), 503-30.

Rubinstein, Yona and Daniel Tsiddon (1998), "Coping with Technological Progress: The Role of Ability in Making Inequality so Persistent", Tel Aviv Foerder Institute for Economic Research and Sackler Institute for Economic Research Working Paper: 27/98

OECD (1994), OECD Jobs Study

Rosen, Sherwin (1981), "The Economics of Superstars", American Economic Review; 71(5), 845-58.

Rosen, Sherwin (1982), "Authority, Control, and the Distribution of Earnings" Bell Journal of Economics; 13(2), 311-23.

Saint-Paul, Gilles (2001), "On the distribution of income and worker assignment under intra-firm spillovers, with an application to ideas and networks", Journal of Political Economy, 109,1, 1-37

Townsend, Robert (1980), "Models of money with spatially separated agents", in J.H. Kareken and N. Wallace, eds, Models of Monetary Economies, Minneapolis: Federal Reserve Bank of Minneapolis, 265-304.

Veneri, Carolyn M. (1998), " Here Today, Jobs of Tomorrow: Opportunities in Information Technology" Occupational Outlook Quarterly

Zeira,Joseph (1999), "Workers, Machines, and Economic Growth" Quarterly Journal of Economics; 113(4), 1091-1117. 



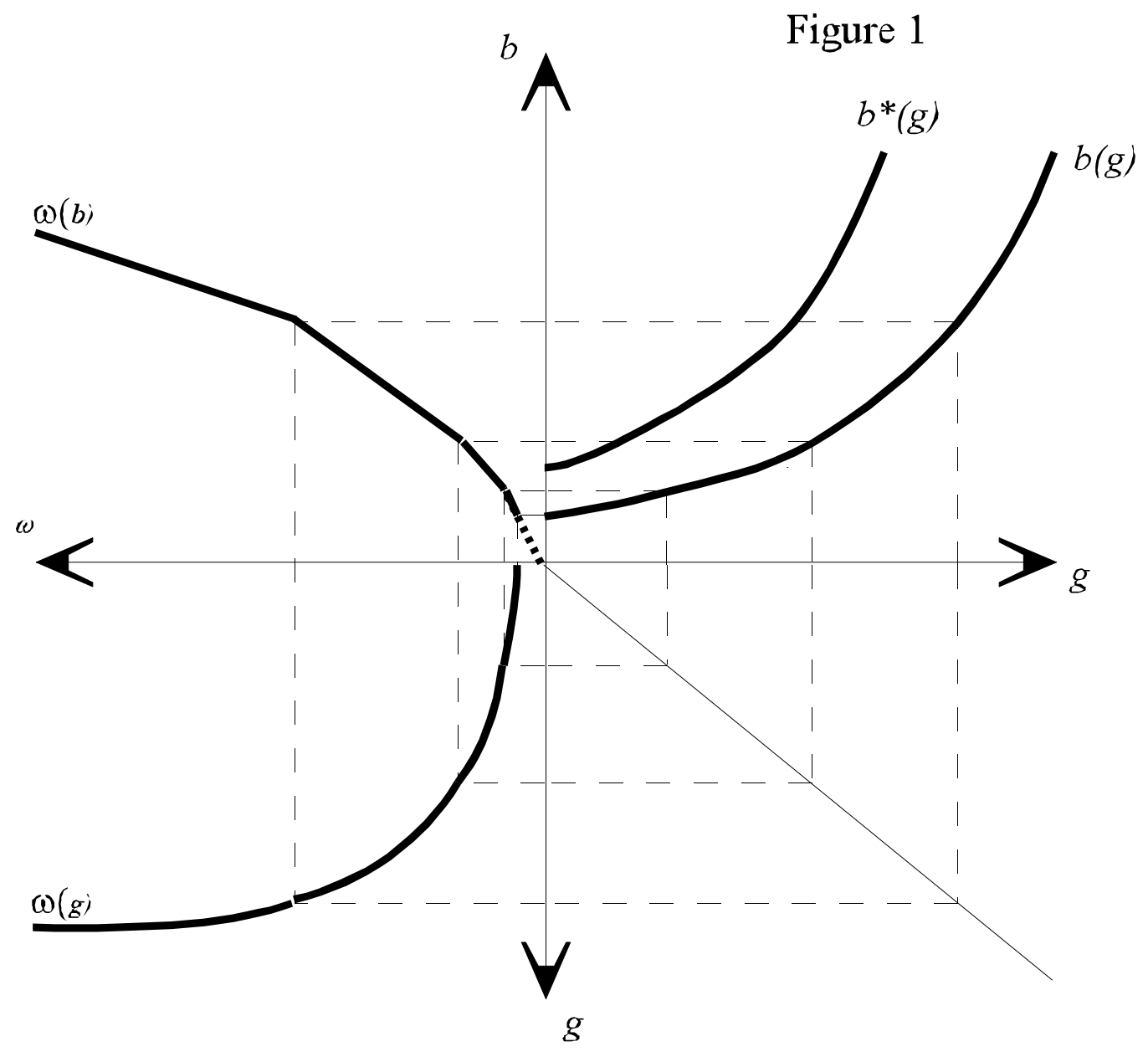




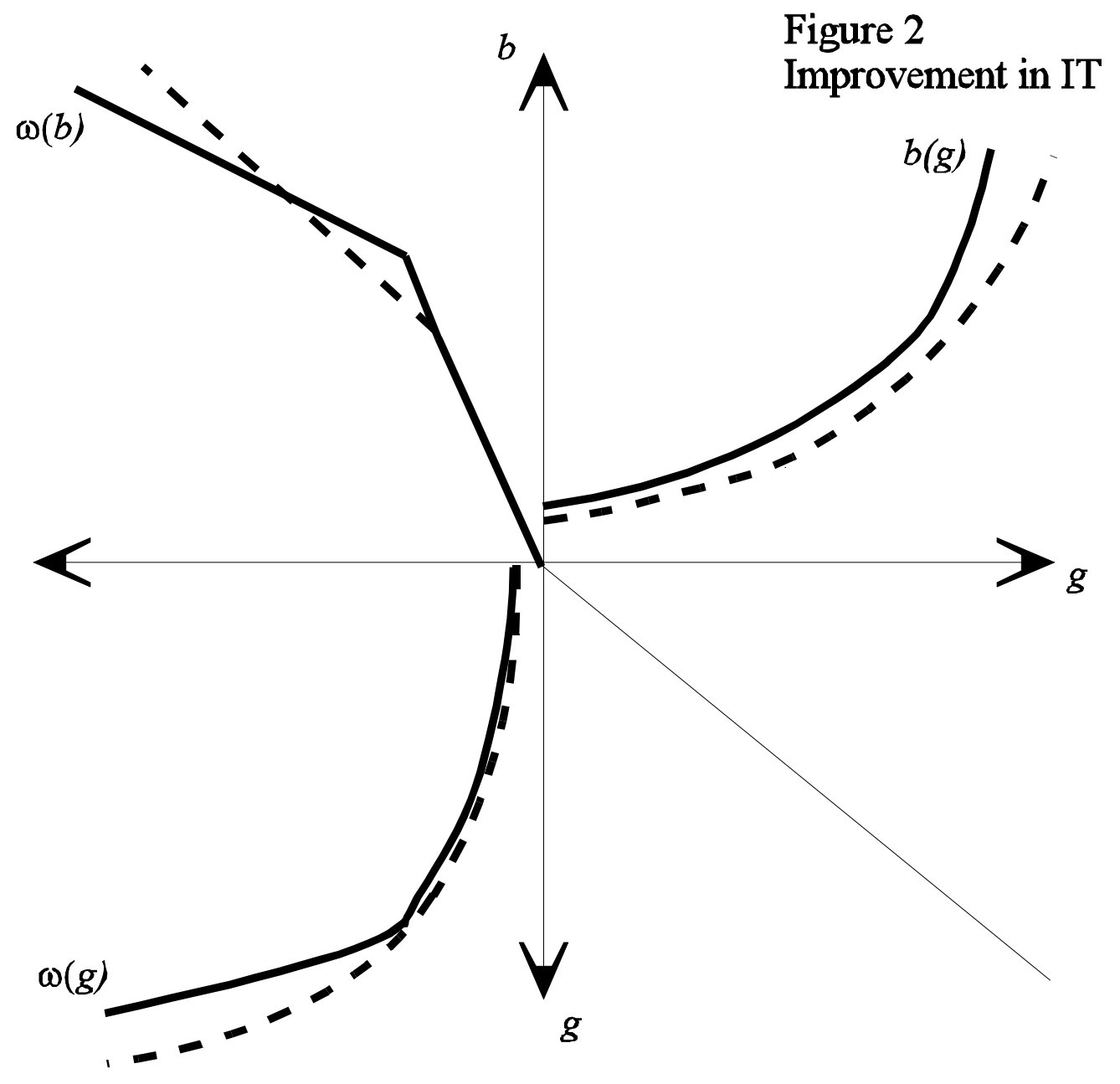




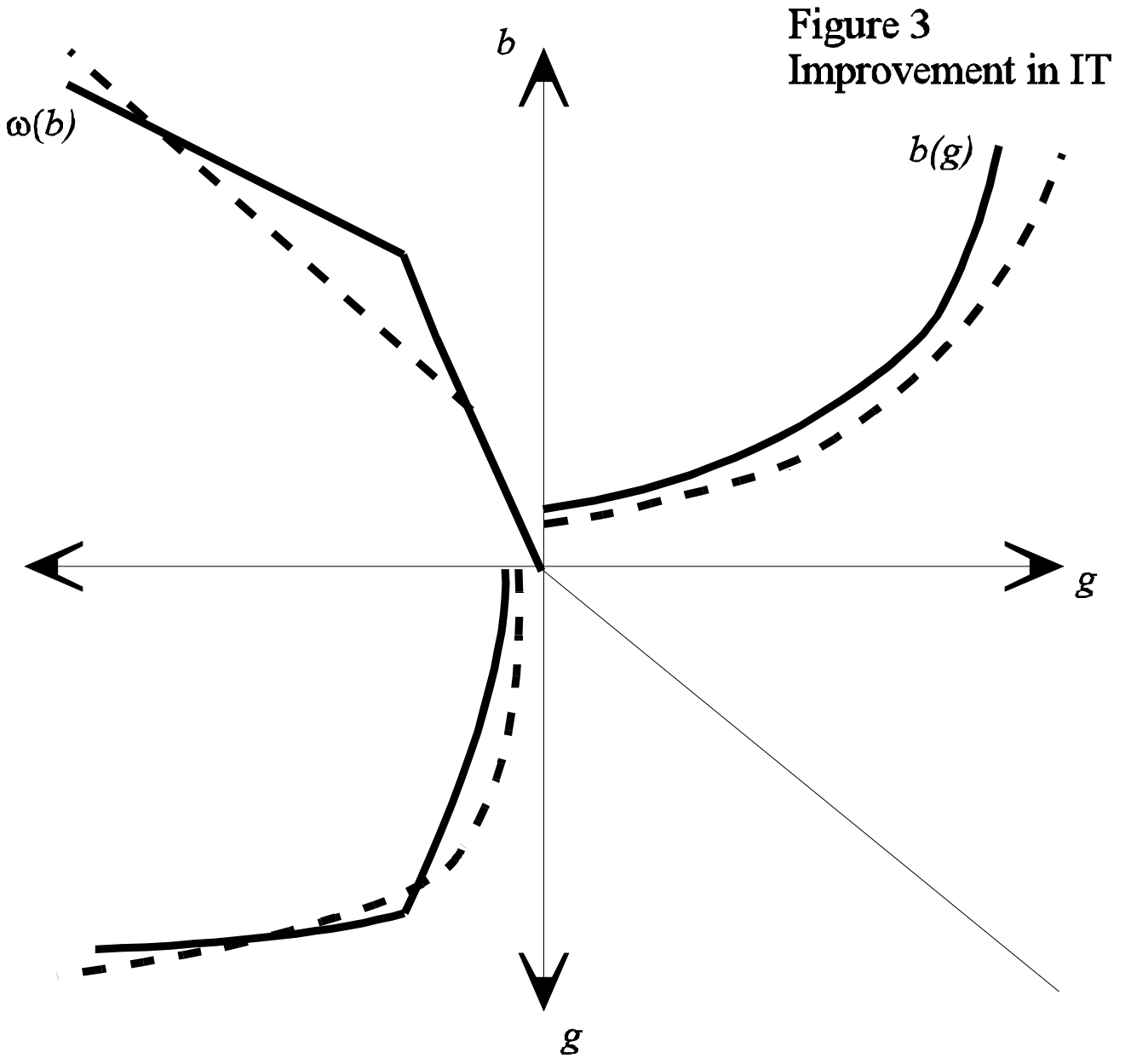

